\title{
Mental retardation associated with congenital heart disease, blepharophimosis, blepharoptosis, and hypoplastic teeth
}

\author{
SHOZO OHDO, HARUMICHI MADOKORO, TOHRU SONODA, AND \\ KUNIO HAYAKA WA \\ From the Department of Pediatrics, Miyazaki Medical College, 5200 Kihara, Kiyotake-cho, Miyazaki \\ 889-16, Japan.
}

SUMMARY We report two sisters with mental retardation, congenital heart disease, blepharophimosis, blepharoptosis, and hypoplastic teeth. A female paternal cousin has the same anomalies, but without congenital heart disease. The chromosomes of these patients are normal and the parents are non-consanguineous.

Among the syndromes of mental retardation associated with congenital heart disease and blepharophimosis are trisomy $18,{ }^{1}$ partial trisomy $10 \mathrm{q},{ }^{2}$ the fetal alcohol syndrome, ${ }^{3}$ and the syndrome reported by Mutchinik. ${ }^{4}$ However, these syndromes clearly differ from the one described in this paper. We were unable to find other reports of subjects with a similar constellation of features.

\section{Case reports}

CASE 1

The proband, a girl, was born on 24.2 .70 to healthy and unrelated parents. The father was 26 and the mother was 27 years old. Although her brother was healthy, her younger sister (case 2) and one of her paternal cousins (case 3) had the same abnormalities.

The mother denied taking drugs or alcohol during pregnancy. Birth weight was $3300 \mathrm{~g}$. At birth, marked blepharophimosis and ptosis were seen. She began to walk at 16 months and by the age of 3 she was able to speak a few words. At the ages of 3 and 5 she underwent operations for blepharophimosis and ptosis.

On physical examination in June 1976, her height was $103.7 \mathrm{~cm}(-1.0 \mathrm{SD})$, weight $16.6 \mathrm{~kg}(-1.1 \mathrm{SD})$, and head circumference $53.5 \mathrm{~cm}(+1.9 \mathrm{SD})$. In spite of two operations, blepharophimosis was still present (fig 1). Her teeth were small, peg-shaped, and widely spaced. The external ear canals were extremely narrow. A preauricular dimple was noted

Received for publication 19 November 1984

Revised version accepted for publication 29 March 1985. on the left side. A grade $4 / 6$ systolic murmur was heard at the lower left sternal border. No abnormality of the abdomen or extremities was observed. Dermatoglyphic study showed the finger patterns to consist of six whorls and four ulnar loops. The atd angle was $54^{\circ}$ on the right palm and $56^{\circ}$ on the left palm.

Routine blood examination, including serum electrolytes, protein, and immunoglobulin levels, proved normal, as did urine analysis. The $\mathrm{G}$ banded karyotype at the 550 band level was normal and the $\mathrm{G}$ banded karyotype of her father was also normal. Her IQ was 49.

Subsequently, she again underwent an operation for blepharophimosis. On 9.10.79 she had an operation for atrial septal defect. She had frequent otitis media and finally hearing impairment was found. Menarche was at 13 years.

On 31.8 .84 her height was $144.9 \mathrm{~cm}(-1.8 \mathrm{SD})$, weight $46.8 \mathrm{~kg}$, and head circumference $54.2 \mathrm{~cm}$. Severe amblyopia was discovered. After three operations for blepharophimosis and ptosis, the eye fissures were almost normal (fig 1). Urine analysis revealed proteinuria $(100 \mathrm{mg} / \mathrm{dl})$, but renal function was normal. Her IQ at that time was 42 .

\section{CASE 2}

The sister of the proband was born on 20.3.74. Her birth weight was $2700 \mathrm{~g}$. At birth she had marked blepharophimosis and ptosis. At 3 months of age, a heart murmur was found by the family physician. She began to walk at 14 months and was over 2 years old when she began to speak a few words.

A medical checkup conducted in June 1976 
showed her height to be $82.5 \mathrm{~cm}(-1 \cdot 3 \mathrm{SD})$, weight $11.8 \mathrm{~kg}$, and head circumference $48.0 \mathrm{~cm}$. Blepharophimosis and ptosis were present (fig 2). Her external auditory canals were not narrow. A grade $3 / 6$ holosystolic murmur was heard at the lower left sternal border. The heart murmur was diagnosed as being due to a ventricular septal defect. Dermatoglyphic study showed the fingertip patterns to consist of four whorls, four ulnar loops, one radial loop, and one arch. The atd angle was $79^{\circ}$ on the right palm and $72^{\circ}$ on the left. The $\mathrm{G}$ banded karyotype, ECG, and chest $x$-ray were normal. The develop- mental quotient was about 60 . She frequently had otitis media. The heart murmur disappeared by the age of 5 .

On 31.8 .84 her height was $126.4 \mathrm{~cm}(-1.5 \mathrm{SD})$, weight $30.9 \mathrm{~kg}$, and head circumference $52.5 \mathrm{~cm}$. In spite of three operations for blepharophimosis and ptosis, these conditions were not fully corrected (fig 2). Mild microphthalmia and severe amblyopia were discovered. Her teeth were small and widely spaced. Hearing impairment was also noted. Her IQ was 37. Although urine analysis detected proteinuria, her renal function was normal.
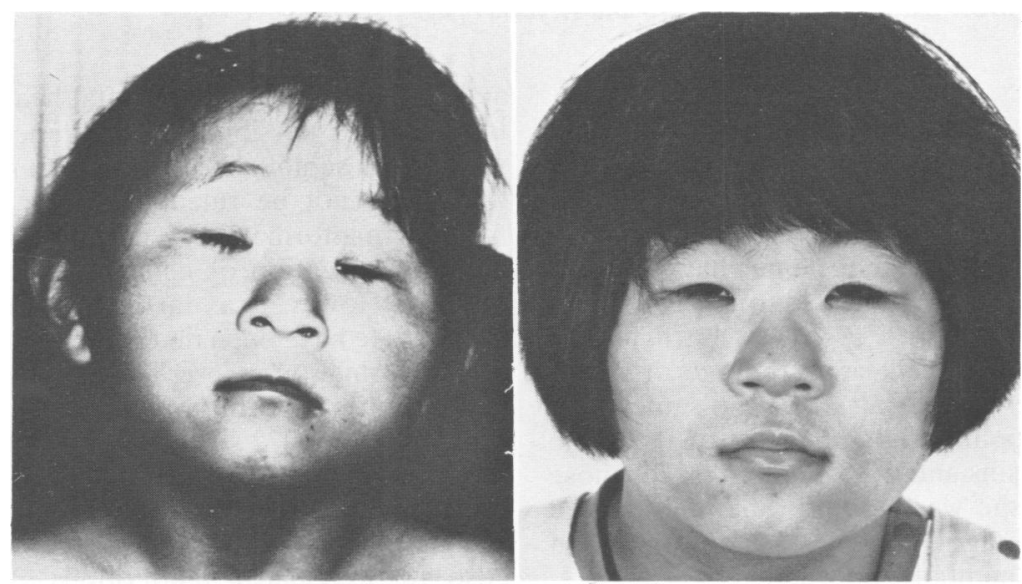

FIG 1 The proband at 5 and 14 years of age.
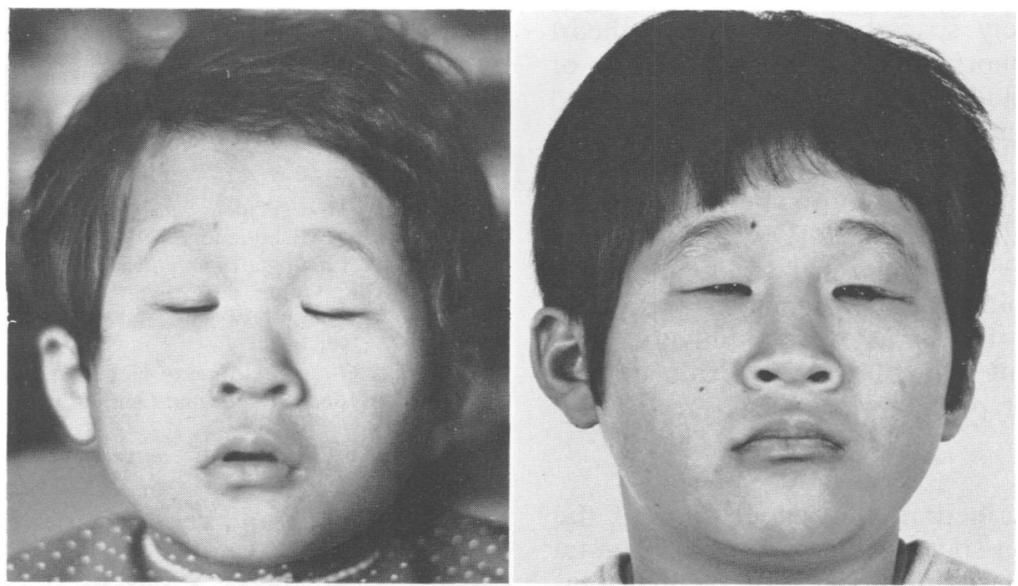

FIG 2 The proband's sister at 2 and 10 years of age. 


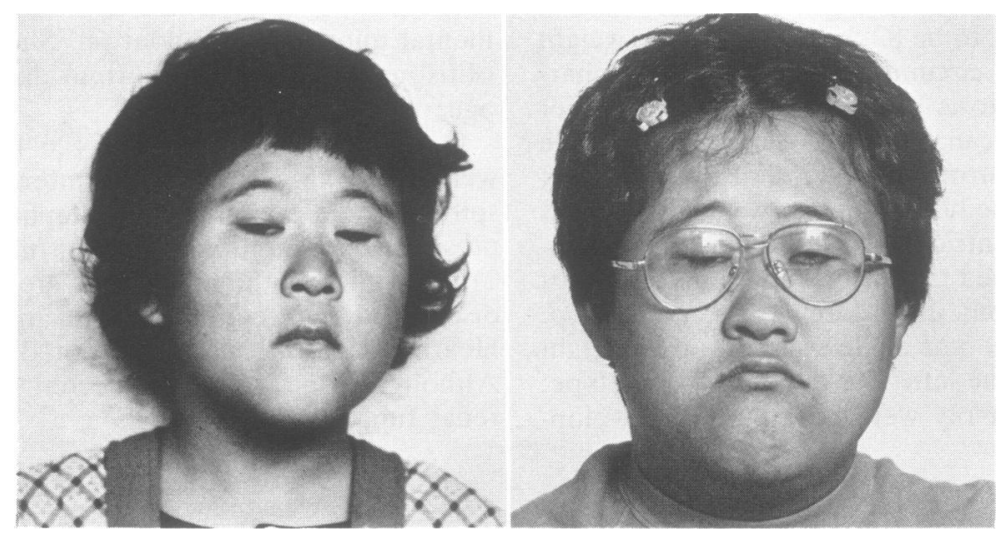

FIG 3 The proband's cousin at 9 and 17 years of age.

CASE 3

The patient was born on 20.1.68 to healthy and unrelated parents. The father was 31 and the mother 29 years of age. The mother is an older sister of the father of the proband. The older brother of the patient is healthy. The mother denies having taken any drug or suffered any illness during pregnancy. The patient was born with asphyxia, birth weight $2300 \mathrm{~g}$. She began to walk after the age of 2 and began to say a few words at about the same time. She had blepharophimosis and ptosis to the same degree as her cousins and was operated on for those conditions when she was 3 and 5. She had marked amblyopia. At the age of 6 , she was admitted to an institute for the mentally retarded.

A medical checkup in the institute in 1976 showed that her physical growth was almost normal. Although the blepharophimosis and ptosis had been improved by the two operations, these conditions could still be seen (fig 3). Her teeth were small, conical, and widely spaced. There was no heart murmur. No abnormality of the abdomen or extremities was noted. Dermatoglyphic study showed the fingertip patterns to consist of five ulnar loops, four radial loops, and one arch. The atd angle was $55^{\circ}$ on the right palm and $53^{\circ}$ on the left. Routine blood tests proved normal. Her IQ was 50 .

In September 1984, her physical development was within normal limits. Blepharophimosis and ptosis were still noted (fig 3) as were amblyopia and hearing impairment. Her IQ was 39 . Urine analysis detected traces of proteinuria.

\section{Discussion}

The patients described in this paper showed the following characteristic combination of congenital anomalies: mental retardation (3/3), blepharophimosis with ptosis (3/3), hypoplastic teeth (3/3), amblyopia (3/3), and congenital heart disease (2/3). In case 3 , the possibility of spontaneous closure of a ventricular septal defect before our first examination could not be ruled out.

Many malformation syndromes associated with mental retardation or congenital heart disease are known. ${ }^{5}$ However, as far as we are able to determine, there have been no reports of the combination of malformations described in this paper. The malformations found in two sisters reported by Mutchinik $^{4}$ in 1972 somewhat resemble those found in our patients. However, the white skin, microcephaly, prognathism, and pigeon breast noted in Mutchinik's cases were not present in our cases. Also, the hypoplastic teeth observed in our patients were not described in Mutchinik's report. ${ }^{4}$

It is impossible to determine the aetiology of the malformation syndrome described in this paper. However, the fact that three patients were found in the same kindred suggests that the syndrome is hereditary. The mode of inheritance is compatible with autosomal recessive inheritance, autosomal dominant inheritance with low penetrance, and multifactorial inheritance.

\section{References}

' Smith DW. Recognizable patterns of human malformation. 3rd ed. Philadelphia: Saunders, 1982:14-7.

2 Schinzel A. Catalogue of unbalanced chromosome aberrations in man. Berlin: Walter de Gruyter, 1984:401-9.

${ }^{3}$ Clarren SK, Smith DW. The fetal alcoholic syndrome. $N$ Engl J Med 1978;298:1063-7.

${ }^{4}$ Mutchinik O. A syndrome of mental and physical retardation, speech disorders and peculiar facies in two sisters. $J$ Med Genet 1972;9:60-3.

5 Bergsma D. Birth defects compendium. 2nd ed. New York: Alan R Liss, 1979.

Correspondence and requests for reprints to Dr $\mathrm{S}$ Ohdo, Department of Pediatrics, Miyazaki Medical College, 5200 Kihara, Kiyotake-cho, Miyazaki 88916, Japan. 